\title{
Discontinuous versus Continuous Weaning in Stroke Patients
}

\author{
Inga K. Teismann ${ }^{a}$ Christian Oelschläger ${ }^{b}$ Nicola Werstler ${ }^{c}$ \\ Catharina Korsukewitz ${ }^{c}$ Jens Minnerup ${ }^{c}$ E.B. Ringelstein ${ }^{c}$ Rainer Dziewas ${ }^{c}$ \\ ${ }^{a}$ Department of Sleep Medicine and Neuromuscular Disorders, Münster, ${ }^{b}$ Department of Neurology, \\ Evangelisches Krankenhaus Bielefeld, Bielefeld, and ${ }^{\mathrm{C}}$ Department of Neurology, Münster, Germany
}

\begin{abstract}
Key Words
Stroke $\cdot$ Weaning $\cdot$ Adaptive support ventilation .

Continuous · Discontinuous · T-piece-trail
\end{abstract}

\begin{abstract}
Background: An increasing number of stroke patients have to be supported by mechanical ventilation in intensive care units (ICU), with a relevant proportion of them requiring gradual withdrawal from a respirator. To date, weaning studies have focused merely on mixed patient groups, COPD patients or patients after cardiac surgery. Therefore, the best weaning strategy for stroke patients remains to be determined. Methods: Here, we designed a prospective randomized controlled study comparing adaptive support ventilation (ASV), a continuous weaning strategy, with biphasic positive airway pressure (BIPAP) in combination with spontaneous breathing trials, a discontinuous technique, in the treatment of stroke patients. The primary endpoint was the duration of the weaning process. Results: Only the 40 (out of 54) patients failing in an initial spontaneous breathing trial (T-piece test) were included into the study; the failure proportion is considerably larger compared to previous studies. Eligible patients were pseudo-randomly assigned to one of the two weaning groups. Both groups did not differ regarding age, gender, and severity of stroke. The results showed that the median weaning duration was 10.7 days ( \pm SD 7.0) in the discontinuous weaning group, and 8 days ( \pm SD 4.5) in the continuous weaning group $(p<0.05)$. Conclusions: To
\end{abstract}

the best of our knowledge, this is the first clinical study to show that continuous weaning is significantly more effective compared to discontinuous weaning in mechanically ventilated stroke patients. We suppose that the reason for the superiority of continuous weaning using ASV as well as the bad performance of our patients in the $2 \mathrm{~h}$ T-piece test is caused by the patients' compliance. Compared to patients on surgical and medical ICUs, neurological patients more often suffer from reduced vigilance, lack of adverse-effects reflexes, dysphagia, and cerebral dysfunction. Therefore, stroke patients may profit from a more gradual withdrawal of weaning.

๑) 2015 S. Karger AG, Basel

\section{Introduction}

Due to new treatment options for severe stroke such as decompressive surgery [1] or hypothermia [2], an increasing number of stroke patients are supported by mechanical ventilation on intensive care units (ICU). It is well known that weaning is problematic in about one fourth to one third of patients in heterogeneous collectives [3-6], usually due to unfavorable respiratory mechanics, residual disease processes, cardiac dysfunction, respiratory muscle weakness, high secretion volumes, or altered mental state [7]. As a consequence, weaning time amounts to $40 \%$

Inga Teismann and Christian Oelschläger contributed equally to this work.

\section{KARGER 125}

(c) 2015 S. Karger AG, Base

$1015-9770 / 15 / 0396-0269 \$ 39.50 / 0$

E-Mail karger@karger.com

www.karger.com/ced
Inga K. Teismann

Department of Sleep Medicine and Neuromuscular Disorders

Albert-Schweitzer-Campus 1, Building A1

DE-48149 Münster (Germany)

E-Mail inga.teismann@ukmuenster.de 
of the duration of mechanical ventilation [8]. Since an undue prolongation of mechanical ventilation is associated with both an increased risk of infectious complications [9] and a higher overall mortality rate $[3,10]$, quick and reliable weaning is of paramount importance. So far, studies investigating different weaning strategies have either included heterogeneous patient groups $[5,11-13]$ or focused on patients with pulmonary disease $[11,14]$ or patients following cardiac surgery $[15,16]$. Moreover, neurologic patients are known to require long ventilation durations and to feature high rates of tracheotomy and mortality compared to non-neurologic patients $[17,18]$.

Interestingly, specific weaning studies have not yet been performed at neurological ICUs, and previous ventilation studies did not focus on the increasing number of ventilated stroke patients. These patients are characterized by a high prevalence of cardiac dysfunction, chronic obstructive lung disease $[19,20]$ and, in up to $21 \%$ of cases, features acute pulmonary complications due to aspiration pneumonia as a complication of dysphagia $[21,22]$. Additionally, severely affected stroke patients usually suffer from reduced vigilance, aphasia, neglect, or delirium [23], all of which may severely impair their compliance with the weaning procedure. Finally, Vallerdu and coworkers noted that in artificially ventilated neurological patients the ability to cough and clear respiratory secretions was significantly more impaired than in groups of patients with COPD or acute respiratory failure [24]. Taken together, one may assume that in stroke patients there is a plethora of both disease-specific and more general obstacles that prevent a successful weaning process.

Based on these considerations, we designed a prospective randomized study comparing two fundamentally different weaning strategies in a collective of ventilated stroke patients. We contrasted biphasic positive airway pressure (BIPAP) with intermittent periods of spontaneous breathing, a discontinuous weaning strategy, which has proven to be the most successful technique in the large study on a mixed group of patients by Esteban et al. [5], with a continuous weaning approach being based on the relatively new tool of adaptive support ventilation (ASV). This technique has limited ventilator settings, needs fewer ventilator adjustments [25], and adjusts to the mechanics of patients' lungs [26]. Therefore, from initial support up to weaning, a sole mode can be used [26]. Due to its smooth and very gradual withdrawal of ventilation, ASV seems to be a reasonable weaning method for difficult-to-wean stroke patients. We hypothesized that continuous weaning using ASV is superior to conventional discontinuous weaning using BIPAP plus spontaneous breathing in ventilated stroke patients.

\section{Methods}

\section{Patients}

We included patients with ischemic and hemorrhagic stroke, who were consecutively recruited over an 18 months period at the neurological ICU of a university hospital in Germany. The stroke diagnosis was confirmed by either computed tomography or magnetic resonance imaging. Further inclusion criteria were artificial ventilation for more than $24 \mathrm{~h}$, failure in the $2 \mathrm{~h}$ spontaneous breathing trial, and dilatational tracheotomy prior to the weaning process. Exclusion criteria were fatal prognosis and cancer.

The following data were collected: anthropometrics, type and localization of stroke, National Institutes of Health - Stroke Scale (NIH-SS) and the Acute Physiological Assessment and Chronic Health Evaluation (APACHE II) scores [27] at admission in our hospital, duration of ICU length of stay, duration of ventilation before weaning onset, and duration of weaning. APACHE II scores were estimated within $24 \mathrm{~h}$ after ICU admission (table 1). The study was carried out in line with ethical principles and approved by the Hospital Ethics Committee. After written informed consent was obtained from the patient (or a legal representative where the patient's communication ability was impaired), each participant was pseudo-randomly assigned to either continuous or discontinuous weaning. Pseudo-randomization was performed directly after patients failed the T-piece-test according to patients' age, gender, and initial NIH-SS with the goal to achieve comparable group means for these parameters.

\section{T-Piece Test}

The T-piece test was performed as previously published [24, 28, 29]. It evaluates the ability of the patient to sustain spontaneous breathing during disconnection from the ventilator with supply of supplemental oxygen and humidification of gas on a T-piece for a maximum of $2 \mathrm{~h}$. The trial was attempted when (1) the patients showed improvement or resolution of the underlying cause of respiratory failure, and (2) the attending physician agreed that the patient was ready to be weaned from the ventilator. In addition, the following criteria were required: (1) body temperature $<38.5^{\circ} \mathrm{C}$, (2) hemoglobin $>8 \mathrm{mg} / \mathrm{dl}$, (3) appropriate cardiovascular pharmacologic therapy, (4) relief from sedation, and (5) correction of electrolyte disorders. The following respiratory criteria were required to start the weaning procedure: (1) arterial oxygen saturation $\geq 95 \%$, (2) $\mathrm{PaO} 2>60 \mathrm{~mm} \mathrm{Hg}$, (3) an inspired oxygen fraction $\leq 40 \%$, (4) $\mathrm{PEEP}$ level $\leq 8 \mathrm{~cm} \mathrm{H}_{2} \mathrm{O}$, (5) maximal inspiratory pressure $\leq 25 \mathrm{~cm} \mathrm{H}_{2} \mathrm{O}$, (6) breathing frequency $\leq 30 / \mathrm{min}$, and (7) vital capacity $\geq 10 \mathrm{ml} / \mathrm{kg}$ of body weight.

The T-piece test was considered unsuccessful if the patient showed any sign of poor clinical tolerance: (1) breathing frequency $>35 / \mathrm{min}$, (2) arterial oxygen saturation $<90 \%$, (3) heart rate $>140$ / min or sustained increase or decrease by $\geq 20 \%$, (4) systolic blood pressure of $>200 \mathrm{~mm} \mathrm{Hg}$ or $<80 \mathrm{~mm} \mathrm{Hg}$ or an increase by $20 \%$ or more, (5) arterial $\mathrm{PO}_{2}<50 \mathrm{~mm} \mathrm{Hg},(6)$ arterial $\mathrm{pH} \leq 7.30$, and (7) when agitation, anxiety, constrained vigilance, or diaphoresis was present. Arterial blood gas tensions were measured (ABL 800flex, Radiometer, Copenhagen, Denmark) 20 min after onset, and at the end of the $2 \mathrm{~h}$ period, and at any moment when clinically required. When no signs of poor clinical tolerance appeared the patient passed the T-piece trail and was not included in the study. Contrariwise, the T-piece trail was considered failed and the patient was randomly assigned to receive either continuous or discontinuous weaning (fig. 1). 
Fig. 1. Course of attribution for stroke pa-

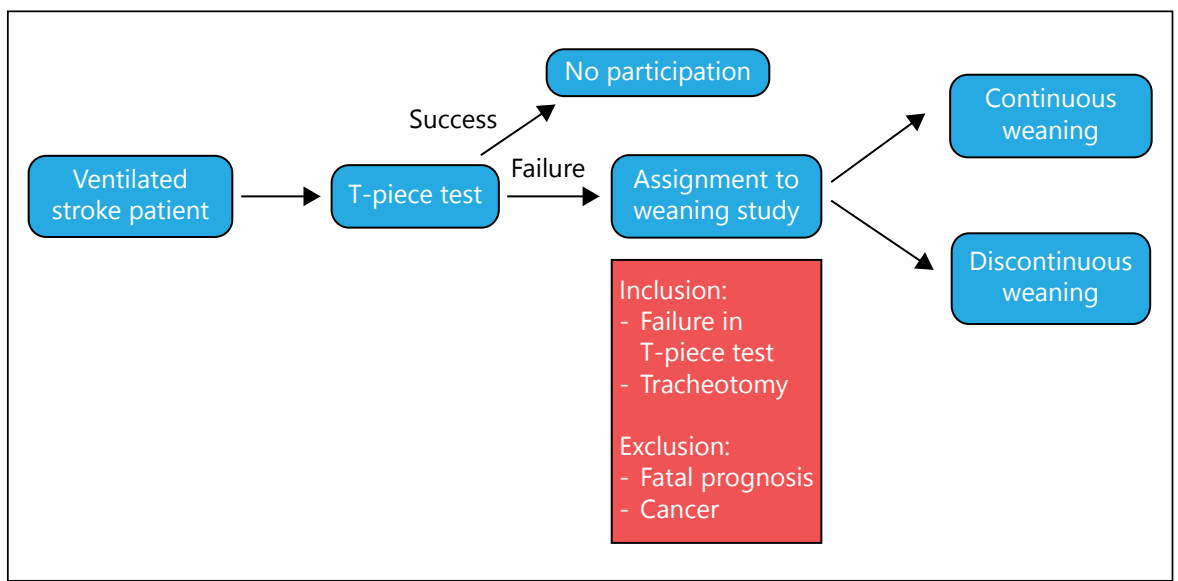
tients.

Table 1. Patient characteristics and prognostic factors

\begin{tabular}{|c|c|c|c|}
\hline Patient characteristics & $\begin{array}{l}\text { Group of patients with } \\
\text { continous weaning } \\
(\mathrm{n}=19)\end{array}$ & $\begin{array}{l}\text { Group of patients with } \\
\text { discontinuous weaning } \\
(\mathrm{n}=20)\end{array}$ & $\mathrm{p}$ value \\
\hline Age, years, mean \pm SD & $67.1 \pm 13.6$ & $62.7 \pm 14.6$ & 0.343 \\
\hline Men, n (\%) & $13(68)$ & $13(65)$ & 1 \\
\hline $\mathrm{NIH}-\mathrm{SS}$ on admission, mean $\pm \mathrm{SD}$ & $12.69 \pm 4.4$ & $11.15 \pm 5.3$ & 0.449 \\
\hline APACHE II on admission, mean \pm SD & $14.2 \pm 5.9$ & $12.7 \pm 5.2$ & 0.417 \\
\hline \multicolumn{4}{|l|}{ Cardiovascular risk factors, $\mathrm{n}(\%)$} \\
\hline Hypertension & $12(63)$ & $13(65)$ & 1 \\
\hline Diabetes mellitus & $3(16)$ & $4(20)$ & 1 \\
\hline Coronary heart disease & $5(26)$ & $7(35)$ & 0.731 \\
\hline Atrial fibrillation & $8(42)$ & $9(45)$ & 1 \\
\hline Smoking & $2(11)$ & $3(15)$ & 1 \\
\hline \multicolumn{4}{|l|}{ Etiology, n (\%) } \\
\hline Bleeding & $6(32)$ & $3(15)$ & 0.273 \\
\hline Atherothrombotic & $4(21)$ & $1(5)$ & 0.182 \\
\hline Embolic & $9(47.4)$ & $10(50)$ & 1 \\
\hline Other etiology & $3(16)$ & $2(10)$ & 0.661 \\
\hline Undetermined etiology & $1(5)$ & $1(5)$ & 1 \\
\hline \multicolumn{4}{|l|}{ Treatment, n (\%) } \\
\hline \multicolumn{4}{|l|}{ Intra-arterial thrombolysis and/or } \\
\hline thrombectomy & $5(26)$ & $7(35)$ & 0.731 \\
\hline Intravenous thromobolysis & $1(5)$ & $2(10)$ & 1 \\
\hline Decompressive surgery & $8(42)$ & $7(35)$ & 0.748 \\
\hline \multicolumn{4}{|l|}{$\begin{array}{l}\text { Reason for failure of the spontaneous } \\
\text { weaning test, } \mathrm{n}(\%)\end{array}$} \\
\hline Tachypnoe & $10(53)$ & $10(50)$ & 1 \\
\hline Hypoxaemia & $6(32)$ & $6(30)$ & 1 \\
\hline Agitation & $2(11)$ & $2(10)$ & 1 \\
\hline Tachycardia & $1(5)$ & $1(5)$ & 1 \\
\hline \multicolumn{4}{|l|}{ Duration of ventilation before beginning } \\
\hline weaning & $7.74(4.7)$ & $8.35(3.6)$ & 0.649 \\
\hline
\end{tabular}

Categorical variables are compared using the Chi-square test. Depending on the scale level of the outcome, groups were compared either by parametric unpaired t-test or by non-parametric Mann-Whitney U test. Data are presented as means $\pm \mathrm{SD}$.

NIH-SS $=$ Stroke Scale of the National Institute of Health. 


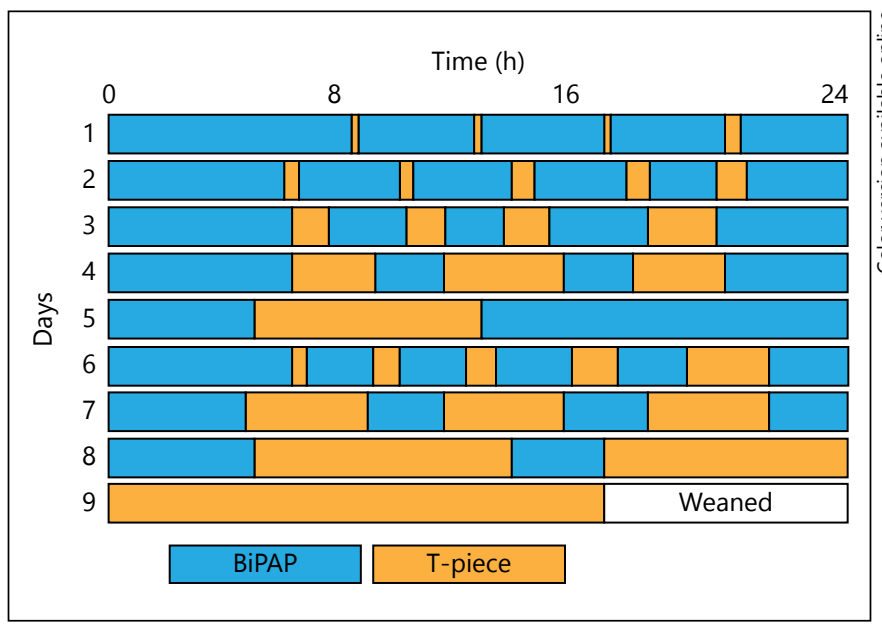

Fig. 2. Example of discontinuous weaning for one patient. Over the first five days, the duration of the spontaneous weaning trials could be increased. On the fifth day, weaning had to be interrupted due to poor clinical tolerance. In the following days, the phases of spontaneous breathing could be extended. The patient was successfully weaned at the ninth day of the study.

\section{Weaning Protocols}

Intermittent Trials of Spontaneous Breathing (Discontinuous Weaning)

BIPAP ventilation is a mode with pressure-regulated, volumecontrolled ventilation, during which spontaneous ventilation can be achieved at any point in the mechanical ventilation-cycle-inspiration or -exhalation [30,31]. The durations of the high- and lowpressure phases as well as the corresponding pressure levels can be adjusted independently [32]. Additionally, BIPAP allows unrestricted spontaneous breathing and by this reduces sedation and promotes weaning. The ventilator maintains a pre-set pressure even when the patient breathes spontaneously. By intermittent release and reapplication of this pressure the tidal volume is generated [33].

Airway pressures were adjusted to deliver a tidal volume of $6-8 \mathrm{ml} / \mathrm{kg}$ predicted body weight. An inspiration:expiration ratio of 1:2 was chosen. Respiratory rate was adjusted to achieve normocapnia. A continuous positive airway pressure of $\leq 8 \mathrm{~cm} \mathrm{H}_{2} \mathrm{O}$ was permitted.

For discontinuous weaning, BIPAP ventilation was used in combination with spontaneous breathing trials. During the ventilation periods, patients were ventilated with an EVITA dura 2 ventilator (Dräger Medical AG, Lübeck, Germany). For the spontaneous breathing trials, patients were disconnected from the ventilator and allowed to breathe spontaneously through a T-tube circuit. These spontaneous trials were performed if arterial $\mathrm{pCO}_{2}$ was $>38$ $\mathrm{mm} \mathrm{Hg}$ and $<50 \mathrm{~mm} \mathrm{Hg}$, and if no sign of poor clinical tolerance as described earlier was observed. Each spontaneous breathing interval was controlled $10 \mathrm{~min}$ later by arterial blood gas tension. The duration of these trials was gradually increased, and they were attempted at least twice a day. Between the spontaneous trials, BIPAP ventilation was provided for at least $1 \mathrm{~h}$ [5]. Patients were classified as successfully weaned when they were able to breathe spontaneously through the T-tube for $24 \mathrm{~h}$ (fig. 2).
Adaptive Support Ventilation (Continuous Weaning)

ASV is a mode with mandatory minute ventilation, where the optimal combination of respiratory rate and tidal volume is calculated by the respirator based on the Otis equation [34], which was first described in 2001 [16, 35]. The target minute ventilation for the individual patient is calculated based on ideal body weight and estimated pulmonary death space. Actual target ventilation can be adjusted by changing the percentage of the initially calculated target for the patient. To achieve the target tidal volume, the ventilator delivers pressure-controlled breaths by adjusting the inspiratory pressure. If the patient breathes spontaneously, ASV changes to pressure support to reach target tidal volume and delivers additional pressure-controlled breaths if the respiratory rate of the patient is below the target rate $[36,37]$. By this, stable minute ventilation and a very low work of breathing can be achieved [38, 39].

Patients weaned by means of ASV were ventilated with a Hamilton Gallileo ventilator (Heinen und Löwenstein GmbH und Co. KG, Bad Ems, Germany). The initial support was chosen as 180 $220 \%$ of min ventilation and an oxygen-inspired fraction of $\leq 40 \%$. Support was adjusted by $20 \%$-steps depending on the arterial blood gas tension results: if arterial $\mathrm{pCO}_{2}$ was $>40 \mathrm{~mm} \mathrm{Hg}$ and $<48$ $\mathrm{mm} \mathrm{Hg}$, and no signs of poor clinical tolerance as described earlier appeared, percent minute ventilation was decreased by $20 \%$. If arterial $\mathrm{pCO}_{2}$ was $<38 \mathrm{~mm} \mathrm{Hg}$ or $>50 \mathrm{~mm} \mathrm{Hg}$, percent minute ventilation was increased by $20 \%$. Each change in the settings of the ventilator was controlled 10 min later by arterial blood gas tension. When patients achieved a support of $80 \%$, they were disconnected from the respirator. Being part of the group of discontinuously weaned patients, they were classified as successfully weaned when they were able to breathe spontaneously through the T-tube for $24 \mathrm{~h}$ (fig. 3).

\section{Statistical Analysis}

Patients were pseudo-randomly assigned to one of the two weaning groups (continuous or discontinuous weaning). Depending on the scale level of the outcome, groups were compared either by parametric unpaired t-test or by non-parametric Mann-Whitney-U test. The Kaplan-Meier estimator was used to determine the duration over which the patients had to be weaned from respiration. The comparison between groups was made using the logrank-test. A p value of 0.05 was considered significance limit. Statistical analysis was performed with IBM-SPSS-Statistics 18 (SPSS Inc., Chicago, Ill., USA).

\section{Results}

During the study period, 54 patients fulfilled the inclusion criteria and performed the $2 \mathrm{~h}$ trial of spontaneous breathing. This trial was successfully completed by 14 patients. The most frequent reason for failure was tachypnoea $(50 \%)$, followed by hypoxemia (30\%), agitation (10\%), and tachycardia (10\%). The remaining 40 patients were randomly assigned to the two weaning groups. One patient in the continuous weaning group died during the weaning process due to neurological complications and was excluded from further calculations. Both weaning 
Fig. 3. Example of continuous weaning for one patient. Over the first four days, the percentage of minute ventilation could be continuously decreased. On the fifth day, weaning had to be interrupted, and the percentage of minute ventilation had to be adapted to $160 \%$ due to bad blood gas samples. In the following days, ventilation support could be further decreased, and the patient was weaned on the ninth day.

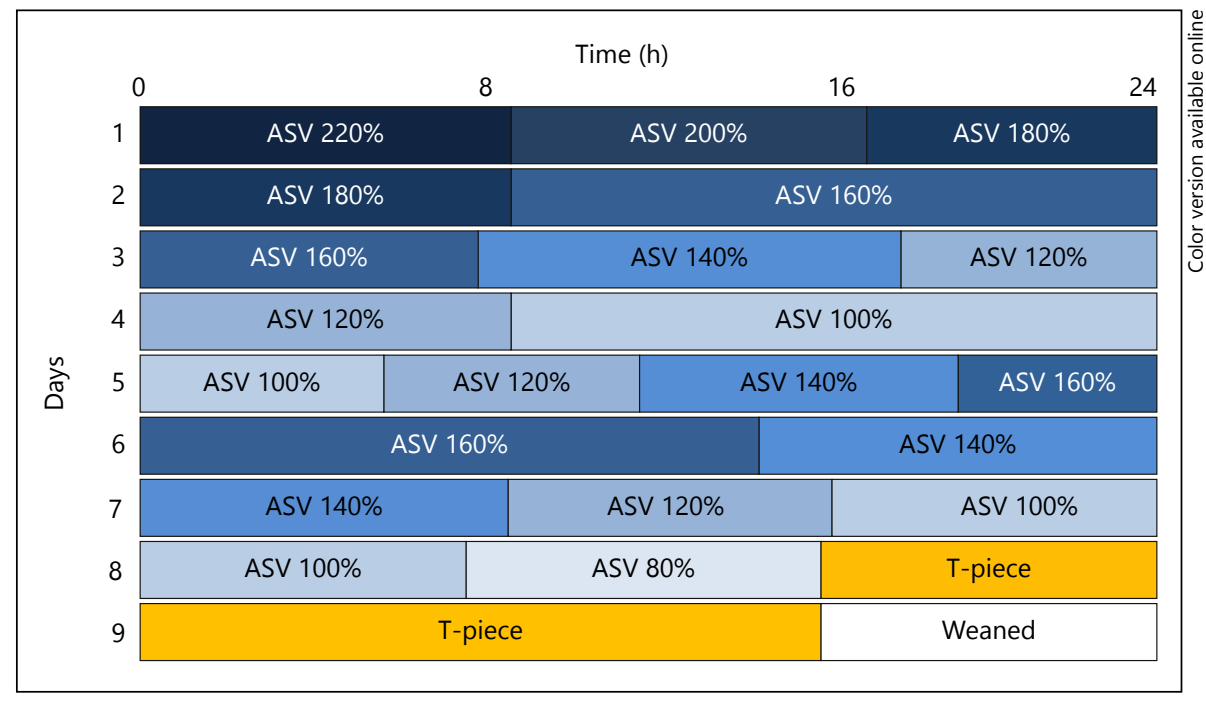

Table 2. Results of the spontaneous weaning trail and outcome variables

\begin{tabular}{lllr}
\hline & $\begin{array}{l}\text { Group of patients with } \\
\text { continuous weaning } \\
(\mathrm{n}=19)\end{array}$ & $\begin{array}{l}\text { Group of patients with } \\
\text { discontinuous weaning } \\
(\mathrm{n}=20)\end{array}$ & p value \\
\hline ICU length of stay in days, SD & $23.2(7.0)$ & $26.25(10.7)$ & $10.7(7.0)$ \\
$\begin{array}{l}\text { Duration of weaning in days, SD } \\
\text { Complications }\end{array}$ & $8.0(4.5)$ & 0.26 \\
$\quad \begin{array}{l}\text { Ventilation associated } \\
\text { Pneumonia, } \mathrm{n}(\%)\end{array}$ & $7(37)$ & $7(35)$ & 0.05 \\
$\quad$ Urinary tract infection, $\mathrm{n}(\%)$ & $1(5)$ & $1(5)$ & 1 \\
\hline
\end{tabular}

Categorical variables are compared using the Chi-square test, ICU length of stay and duration of weaning are compared using the log-rank test.

groups were well matched with respect to age, gender, and severity of stroke. They were also comparable regarding underlying disease, reason for intubation, reason for failure of T-piece test, and the indication for mechanical ventilation. Groups did not differ regarding the duration of ventilation before the onset of weaning, the overall duration of ICU length of stay, and the initial NIH-SS and the APACHE II scores ( $\mathrm{p}>0.05)$ (table 1).

Weaning took 3-25 days in the discontinuous weaning group (mean 10.7 days; SD 7.0) and 3-20 days in the continuous weaning group (mean 8.0 days; SD 4.5). The mean weaning time from mechanical ventilation was significantly longer in the discontinuous than in the continuous weaning group (log-rank-test: $\mathrm{p}<0.05$ ) (fig. 4).

Seven patients in the continuous weaning group and 6 patients in the discontinuous weaning group developed

Discontinuous versus Continuous

Weaning in Stroke Patients a ventilation-associated pneumonia (VAP) and required antibiotic therapy during the weaning process. In those patients, weaning from mechanical ventilation took significantly longer compared to patients without VAP ( $\mathrm{p}<$ 0.001 ). One patient in each group needed antibiotic therapy due to a urinary tract infection during the weaning process (table 2). Weaning was not prolonged in these two patients ( 5 respectively 4 days of weaning). No correlation was found between age and weaning duration $(\mathrm{p}>0.05)$.

\section{Discussion}

In the present study, we compared continuous vs. discontinuous weaning strategies in a group of patients with acute hemorrhagic or ischemic stroke requiring artificial 


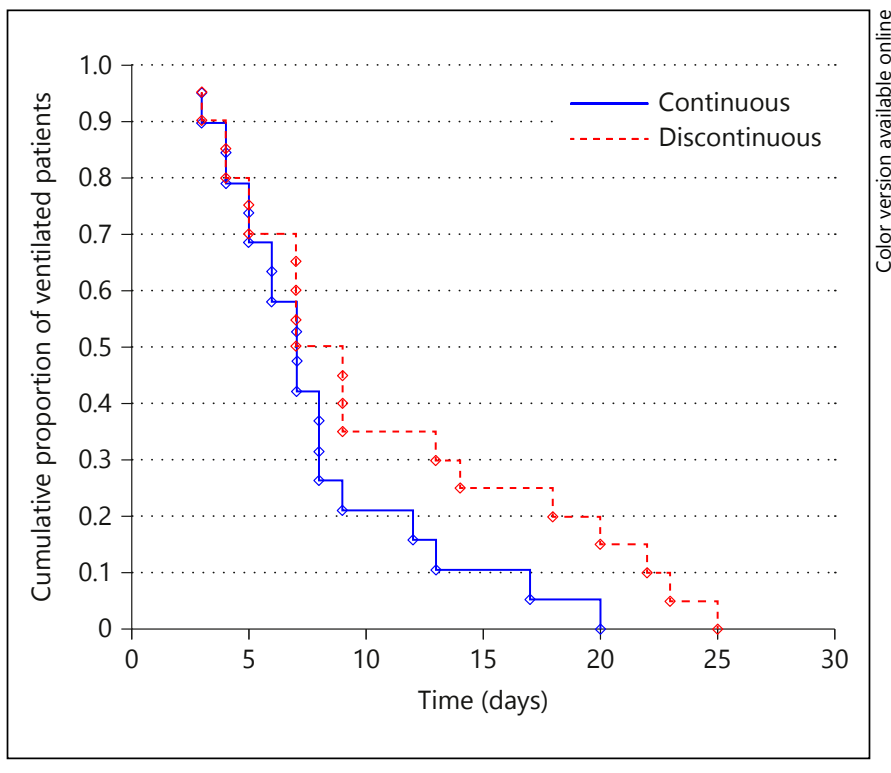

Fig. 4. Kaplan-Meier-graph showing the percentage of ventilated patients in the continuous (blue line) and discontinuous (red dashed line) weaning groups for each day following weaning onset $(\mathrm{p}<0.05)$.

ventilation. This study yielded two main findings. First, a high proportion $(74 \%)$ of stroke patients in need of mechanical ventilation profited from a stepwise separation from the ventilator. Second, ASV, a form of continuous weaning, was more effective and significantly faster than discontinuous weaning via BIPAP in combination with spontaneous breathing. To the best of our knowledge, this is the first study to compare different weaning strategies in ventilated stroke patients.

One study could show that a spontaneous breathing trial over $2 \mathrm{~h}$ is not superior to a spontaneous breathing trail of only $30 \mathrm{~min}$ [40]. Due to the numerous problems of ventilated stroke patients, we decided to choose the more conservative spontaneous breathing trail of $2 \mathrm{~h}$ to reduce the reintubation rate. Noteworthy is the fact that in the current study only $26 \%$ of the patients could be taken off the respirator as soon as no medical indication for further ventilation was present. This proportion is considerably lower compared to what was found in previous studies with other patient groups. In the largest weaning study to date that employed a mixed medical-surgical collective of 546 patients, $76 \%$ of the participants were successful in spontaneous weaning [5]. In a similar study with a mixed group of 456 patients, Brochard and coworkers could also show primarily successful spontaneous weaning also in $76 \%$ of the patients [4]. In COPD patient samples, fewer subjects could be weaned sponta- neously. After at least $24 \mathrm{~h}$ of mechanical ventilation, $54 \%$ of the patients could be taken off the respiration in the first attempt [8]. After at least 15 days of mechanical ventilation, a spontaneous breathing trial was successful in $31 \%$ of COPD patients [11]. In COPD patients, lung function is the limiting factor that leads to a reduced spontaneous weaning rate. In the current study, $50 \%$ of patients failed in the T-piece test due to tachypnoea without substantial changes of blood gases. Pulmonary insufficiency, documented as hypoxemia, was the reason for failure in only $30 \%$ of patients. We therefore conclude that compliance with the spontaneous breathing trial is one critical feature characterizing our patient collective. Based on previous findings reporting that 105 out of 589 extubated patients had a preextubation respiratory rate $>30$ breaths/ min [41], one might suppose that spontaneous breathing would have principally been possible in some of our patients. However, due to obvious vegetative stress and the patients' impaired insight into the actual clinical condition, such a procedure seems questionable in stroke patients.

The second main finding of our study suggests that continuous weaning using ASV leads to a faster weaning of stroke patients compared to discontinuous weaning using alternating phases of BIPAP and spontaneous breathing. Previous studies with mixed surgical-medical collectives comparing different weaning strategies revealed the superiority of intermittent trials of spontaneous breathing compared to both intermittent mandatory ventilation and pressure-support ventilation [5], while Brochard and coworkers showed that Pressure Support Ventilation (PSV) with reduction of pressure support twice a day led to significantly shorter weaning duration compared to intermittent t-tests or Synchronized Intermittent Mandatory Ventilation (SIMV) [4].

In long-term ventilated COPD patients, discontinuous weaning and decreasing levels of PSV were equipollent [11], while in shorter-term ventilated COPD patients decreasing support of PSV was even superior to discontinuous weaning [8]. Altogether, the results of prior weaning studies with mixed patient groups and studies with chronic pulmonary disease patients are inconsistent. While the largest study demonstrated the superiority of discontinuous weaning [5], studies on pulmonary ill subjects showed faster weaning using PSV $[8,11]$.

ASV, a novel closed loop mechanical ventilation strategy, has already demonstrated its efficiency and safety $[42,43]$. Promising weaning results were found in different groups of patients. It could be shown that ASV 
is not inferior to conventional ventilation modes [25, $44]$, and that it even led to shorter ventilation times in both patients after cardiac surgery $[15,16,45]$ and COPD patients [46]. First results even demonstrated a weaning success rate of nearly $50 \%$ in chronically ventilated patients using ASV as the sole mode [47]. In that study, a mixed group of 27 medical and neurologic patients was included. Each patient was mechanically ventilated for at least 3 months and had at least one failed weaning attempt. ASV support was reduced weekly, until patients could be disconnected from the respirator. Twelve out of 27 patients could be weaned within two months. Little is known about weaning with ASV mode in patients with cerebral injury. In a small collective of 12 brain injured patients, ASV mode provided normoventilation in 8 patients. In the remaining 4 patients, hyperventilation with $\mathrm{CO}_{2}$ decrease due to brainstem irritation occurred [48]. The big advantage of ASV is the patients' ability to decide how much support is needed at any time of artificial ventilation. In our study we wanted to compare the standard weaning method for discontinuous weaning with this new continuous method. With an average of 9 days, weaning took longer in the current study than in the previous study by Esteban and coworkers, who reported a mean weaning duration of 4 days [5]. The list of factors that can lead to weaning failure and prolonged weaning in surgical and medical patients is very long [49]. In neurologic patients, reduced vigilance, lack of defense reflexes, dysphagia, and cerebral dysfunction are observed regularly. Further complications including aphasia, neglect, delirium [23], critical-illness-polyneuropathy, critical-illness-myopathy, and neuropsychiatric symptoms [50] prolong the weaning duration in neurologic patients. Additionally, patients with hemorrhagic or ischemic stroke that need mechanical ventilation are mainly elderly and present with complications such as cardiac dysfunction and chronic and acute pulmonary complications [19-22]. All these factors may help to explain the worse weaning compliance of stroke patients compared to surgical or medical patients.

The question arises why continuous weaning using ASV is superior to conventional discontinuous weaning in stroke patients. We suppose that this is mainly caused by patients' compliance. As mentioned earlier, neurological patients more often suffer from reduced vigilance, lack of defense reflexes, dysphagia, and cerebral dysfunction compared to patients on surgical and medical ICUs. Therefore, stroke patients seem to profit from a more gradual withdrawal of weaning, where the stepwise re-

Discontinuous versus Continuous

Weaning in Stroke Patients duction of ventilator support is not really noticeable by patients.

In accordance with previous observations $[51,52]$, the risk for VAP was directly proportional to weaning duration. In the present data, six (respectively seven) patients in each group developed a VAP requiring antibiotic treatment. Weaning was significantly prolonged in those patients. Additionally, one patient per group suffered from urinary tract infection without any effect on weaning duration. Altogether, there were no statistically significant differences in complication rates between the continuous vs. discontinuous weaning groups.

\section{Limitations}

The small sample size is the main limitation of the present study. This might also explain the missing correlation between age and duration of weaning. Additionally, no conclusions can be drawn regarding concurrent continuous weaning modes. In future studies, different continuous and discontinuous weaning modes should be compared in larger collectives of stroke patients, and additional predictors for weaning success should be observed in more detail. Additionally, different continuous weaning modes like slow reduction of pressure support and ASV should be compared. Nevertheless, the present study gives a first insight into the weaning of the difficult-to-wean group of ventilated stroke patients.

\section{Summary}

Our study is, to our knowledge, the first to evaluate the effectiveness of different weaning modes in mechanically ventilated stroke patients. Compared to surgical and medical ICU patients, stroke patients more often fail in a spontaneous breathing trial after long-term ventilation and therefore profit from a stepwise separation from the ventilator. In these cases, continuous weaning using adaptive support ventilation offers a benefit, crystallizing in the reduced duration of mechanical ventilation and weaning times.

\section{Acknowledgments}

We thank Henning Teismann for providing valuable comments on a previous version of this manuscript. 


\section{References}

1 Vahedi K, Hofmeijer J, Juettler E, Vicaut E, George B, Algra A, Amelink GJ, Schmiedeck P, Schwab S, Rothwell PM, Bousser MG, van der Worp HB, Hacke W: Early decompressive surgery in malignant infarction of the middle cerebral artery: a pooled analysis of three randomised controlled trials. Lancet Neurol 2007;6:215-222.

-2 Kollmar R, Blank T, Han JL, Georgiadis D, Schwab S: Different degrees of hypothermia after experimental stroke: short- and long-term outcome. Stroke 2007;38:15851589.

$>3$ Epstein SK: Weaning from ventilatory support. Curr Opin Crit Care 2009;15:36-43.

4 Brochard L, Rauss A, Benito S, Conti G, Mancebo J, Rekik N, Gasparetto A, Lemaire F: Comparison of three methods of gradual withdrawal from ventilatory support during weaning from mechanical ventilation. Am J Respir Crit Care Med 1994;150:896-903.

5 Esteban A, Frutos F, Tobin MJ, Alia I, Solsona JF, Valverdu I, Fernandez R, de la Cal MA, Benito S, Tomas R, et al: A comparison of four methods of weaning patients from mechanical ventilation. Spanish lung failure collaborative group. N Engl J Med 1995;332: 345-350.

6 Eskandar N, Apostolakos MJ: Weaning from mechanical ventilation. Crit Care Clin 2007; 23:263-274, $x$.

7 Ferguson A: Weaning patients off invasive ventilation. BMJ 2009;338:b728.

$\checkmark 8$ Matic I, Danic D, Majeric-Kogler V, Jurjevic M, Mirkovic I, Mrzljak Vucinic N: Chronic obstructive pulmonary disease and weaning of difficult-to-wean patients from mechanical ventilation: randomized prospective study. Croat Med J 2007;48:51-58.

\$9 Torres A, Aznar R, Gatell JM, Jimenez P, Gonzalez J, Ferrer A, Celis R, Rodriguez-Roisin R: Incidence, risk, and prognosis factors of nosocomial pneumonia in mechanically ventilated patients. Am Rev Respir Dis 1990;142: 523-528.

10 Tobin MJ: Mechanical ventilation. N Engl J Med 1994;330:1056-1061.

-11 Vitacca M, Vianello A, Colombo D, Clini E, Porta R, Bianchi L, Arcaro G, Vitale G, Guffanti E, Lo Coco A, Ambrosino N: Comparison of two methods for weaning patients with chronic obstructive pulmonary disease requiring mechanical ventilation for more than 15 days. Am J Respir Crit Care Med 2001;164: 225-230.

12 Burns KE, Lellouche F, Loisel F, Slutsky AS, Meret A, Smith O, Saskin R, Meade M: Weaning critically ill adults from invasive mechanical ventilation: a national survey. Can J Anaesth 2009;56:567-576.

$\checkmark 13$ Hess D: Ventilator modes used in weaning. Chest 2001;120:474S-476S.

14 Nava S, Rubini F, Zanotti E, Ambrosino N, Bruschi C, Vitacca M, Fracchia C, Rampulla C: Survival and prediction of successful ven- tilator weaning in COPD patients requiring mechanical ventilation for more than 21 days. Eur Respir J 1994;7:1645-1652.

$>15$ Gruber PC, Gomersall CD, Leung P, Joynt GM, Ng SK, Ho KM, Underwood MJ: Randomized controlled trial comparing adaptivesupport ventilation with pressure-regulated volume-controlled ventilation with automode in weaning patients after cardiac surgery. Anesthesiology 2008;109:81-87.

16 Sulzer CF, Chiolero R, Chassot PG, Mueller $\mathrm{XM}$, Revelly JP: Adaptive support ventilation for fast tracheal extubation after cardiac surgery: a randomized controlled study. Anesthesiology 2001;95:1339-1345.

17 Pelosi P, Ferguson ND, Frutos-Vivar F, Anzueto A, Putensen C, Raymondos K, Apezteguia C, Desmery P, Hurtado J, Abroug F, Elizalde J, Tomicic V, Cakar N, Gonzalez M, Arabi Y, Moreno R, Esteban A: Management and outcome of mechanically ventilated neurologic patients. Crit Care Med 2011;39: 1482-1492.

18 Steffling D, Ritzka M, Jakob W, Steinbrecher A, Schwab-Malek S, Kaiser B, Hau P, Boy S, Fuchs K, Bogdahn U, Schlachetzki F: [Indications and outcome of ventilated patients treated in a neurological intensive care unit]. Nervenarzt 2012;83:741-750.

19 Ingeman A, Andersen G, Hundborg HH, Svendsen ML, Johnsen SP: In-hospital medical complications, length of stay, and mortality among stroke unit patients. Stroke 2011; 42:3214-3218.

20 Rabinstein AA, Wijdicks EF: Outcome of survivors of acute stroke who require prolonged ventilatory assistance and tracheostomy. Cerebrovasc Dis 2004; 18:325-331.

-21 Hilker R, Poetter C, Findeisen N, Sobesky J, Jacobs A, Neveling M, Heiss WD: Nosocomial pneumonia after acute stroke: implications for neurological intensive care medicine. Stroke 2003;34:975-981.

22 Dziewas R, Ritter M, Schilling M, Konrad C, Oelenberg S, Nabavi DG, Stogbauer F, Ringelstein EB, Ludemann P: Pneumonia in acute stroke patients fed by nasogastric tube. J Neurol Neurosurg Psychiatry 2004;75:852856.

23 Pilato F, Profice P, Dileone M, Ranieri F, Capone F, Minicuci G, Tagliente D, Florio L, Di Iorio R, Plantone D, Tonali PA, Di Lazzaro V: Stroke in critically ill patients. Minerva Anestesiol 2009;75:245-250.

24 Vallverdu I, Calaf N, Subirana M, Net A, Benito S, Mancebo J: Clinical characteristics, respiratory functional parameters, and outcome of a two-hour T-piece trial in patients weaning from mechanical ventilation. Am J Respir Crit Care Med 1998;158:18551862.

25 Petter AH, Chiolero RL, Cassina T, Chassot PG, Muller XM, Revelly JP: Automatic 'respirator/weaning' with adaptive support ventilation: the effect on duration of endotracheal intubation and patient management. Anesth Analg 2003;97:1743-1750.

26 Arnal JM, Wysocki M, Nafati C, Donati S, Granier I, Corno G, Durand-Gasselin J: Automatic selection of breathing pattern using adaptive support ventilation. Intensive Care Med 2008;34:75-81.

27 Knaus WA, Draper EA, Wagner DP, Zimmerman JE: APACHE II: a severity of disease classification system. Crit Care Med 1985;13: 818-829.

28 Esteban A, Alia I, Tobin MJ, Gil A, Gordo F, Vallverdu I, Blanch L, Bonet A, Vazquez A, de Pablo R, Torres A, de La Cal MA, Macias S: Effect of spontaneous breathing trial duration on outcome of attempts to discontinue mechanical ventilation. Spanish lung failure collaborative group. Am J Respir Crit Care Med 1999;159:512-518.

29 Esteban A, Alia I, Gordo F, Fernandez R, Solsona JF, Vallverdu I, Macias S, Allegue JM, Blanco J, Carriedo D, Leon M, de la Cal MA, Taboada F, Gonzalez de Velasco J, Palazon E, Carrizosa F, Tomas R, Suarez J, Goldwasser RS: Extubation outcome after spontaneous breathing trials with T-tube or pressure support ventilation. The Spanish lung failure collaborative group. Am J Respir Crit Care Med 1997;156:459-465.

30 Baum M, Benzer H, Putensen C, Koller W, Putz G: [Biphasic positive airway pressure (BIPAP) - a new form of augmented ventilation]. Anaesthesist 1989;38:452-458.

-31 Schirmer U, Calzia E, Lindner KH, Goertz A Georgieff M: Right ventricular function during weaning from respirator after coronary artery bypass grafting. Comparison of two different weaning techniques. Chest 1994; 105:1352-1356.

32 Hormann C, Baum M, Putensen C, Mutz NJ, Benzer H: Biphasic positive airway pressure (BIPAP) - a new mode of ventilatory support. Eur J Anaesthesiol 1994;11:37-42.

-33 Mireles-Cabodevila E, Diaz-Guzman E, Heresi GA, Chatburn RL: Alternative modes of mechanical ventilation: a review for the hospitalist. Cleve Clin J Med 2009;76:417-430.

34 Otis AB, Fenn WO, Rahn H: Mechanics of breathing in man. J Appl Physiol 1950;2:592607.

35 Campbell RS, Branson RD, Johannigman JA: Adaptive support ventilation. Respir Care Clin N Am 2001; 7:425-440, ix.

-36 Laubscher TP, Frutiger A, Fanconi S, Jutzi H, Brunner JX: Automatic selection of tidal volume, respiratory frequency and minute ventilation in intubated ICU patients as start up procedure for closed-loop controlled ventilation. Int J Clin Monit Comput 1994;11:1930.

-37 Linton DM, Potgieter PD, Davis S, Fourie AT, Brunner JX, Laubscher TP: Automatic weaning from mechanical ventilation using an adaptive lung ventilation controller. Chest 1994;106:1843-1850. 
38 Tassaux D, Dalmas E, Gratadour P, Jolliet P: Patient-ventilator interactions during partial ventilatory support: a preliminary study comparing the effects of adaptive support ventilation with synchronized intermittent manda tory ventilation plus inspiratory pressure support. Crit Care Med 2002;30:801-807.

39 Dojat M, Harf A, Touchard D, Lemaire F, Brochard L: Clinical evaluation of a computer-controlled pressure support mode. Am J Respir Crit Care Med 2000;161:1161-1166.

40 Perren A, Domenighetti G, Mauri S, Genini F, Vizzardi N: Protocol-directed weaning from mechanical ventilation: clinical outcome in patients randomized for a 30-min or 120-min trial with pressure support ventilation. Intensive Care Med 2002;28:1058-1063.

41 DeHaven CB, Kirton OC, Morgan JP, Hart AM, Shatz DV, Civetta JM: Breathing measurement reduces false-negative classification of tachypneic preextubation trial failures. Crit Care Med 1996;24:976-980.

42 Brunner JX, Iotti GA: Adaptive support ventilation (ASV). Minerva Anestesiol 2002;68: 365-368.
43 Sulemanji D, Marchese A, Garbarini P, Wysocki M, Kacmarek RM: Adaptive support ventilation: an appropriate mechanical ventilation strategy for acute respiratory distress syndrome? Anesthesiology 2009; 111:863870.

44 Iotti GA, Polito A, Belliato M, Pasero D, Beduneau G, Wysocki M, Brunner JX, Braschi A, Brochard L, Mancebo J, Ranieri VM, Richard JC, Slutsky AS: Adaptive support ventilation versus conventional ventilation for total ventilatory support in acute respiratory failure. Intensive Care Med 2010;36:1371-1379.

45 Cassina T, Chiolero R, Mauri R, Revelly JP: Clinical experience with adaptive support ventilation for fast-track cardiac surgery. J Cardiothorac Vasc Anesth 2003;17:571-575.

46 Kirakli C, Ozdemir I, Ucar ZZ, Cimen P, Kepil S, Ozkan SA: Adaptive support ventilation for faster weaning in COPD: a randomised controlled trial. Eur Respir J 2011; 38:774-780.
47 Linton DM, Renov G, Lafair J, Vasiliev L, Friedman G: Adaptive support ventilation as the sole mode of ventilatory support in chronically ventilated patients. Crit Care Resusc 2006;8:11-14.

48 Polupan AA, Goriachev AS, Savin IA, Satishur OE, Oshorov AV, Popugaev KA, Sychev AA, Tabasaranskii TF, Krylov K, Sokolova E, Mezntseva O: [First experience of using adaptive support ventilation (ASV) mode in patients with severe traumatic brain injury]. Anesteziol Reanimatol 2011;4:46-50.

49 Alia I, Esteban A: Weaning from mechanical ventilation. Crit Care 2000;4:72-80.

50 Oehmichen F, Pohl M, Schlosser R, Stogowski D, Toppel D, Mehrholz J: [Critical illness polyneuropathy und polymyopathy. How certain is the clinical diagnosis in patients with weaning failure?]. Nervenarzt 2012;83:220-225.

51 Davis KA: Ventilator-associated pneumonia: a review. J Intensive Care Med 2006;21:211226.

52 Bouadma L, Wolff M, Lucet JC: Ventilatorassociated pneumonia and its prevention. Curr Opin Infect Dis 2012;25:395-404. 